\title{
РЕЧЕВАЯ АГРЕССИЯ В КОММЕНТАРИЯХ СОЦИАЛЬНЫХ СЕТЕЙ И МОНИТОРИНГ СОЦИАЛЬНОЙ НАПРЯЖЕННОСТИ (НА МАТЕРИАЛЕ КОММЕНТАРИЕВ В ПРОФИЛЕ @KUZВASS_NEWS )'
}

\section{VERBAL AGGRESSION IN SOCIAL MEDIA COMMENTS AND MONITORING OF SOCIAL TENSION (AS EXEMPLIFIED BY COMMENTS IN @KUZBASS_NEWS )}

\section{Falomkina}

Summary: In the article, comments of Instagram users are analyzed from the point of view of aggressive behavior, which, in opinion of the author, on the one hand can be explained by the specifics of communication in Internet, which is deprived of a whole number of communication restrictions, by the virtual nature of communication and anonymity, and on the other hand is a marker of social tension: the level of verbal aggression is directly dependent on the level of interest to the content of a publication, and that means on the significance of the event covered in the text for the commentator. Most emotional topics for Kuzbass region population in the period from 1 March, 2019 until 1 March, 2020 were the bad environmental situation, mass migration of people from the region, low level of the population's income, and the irrational distribution of the local budget.

The work touches upon the subject of the genre specifics of internet comment, the phenomenon of verbal aggression is defined, and the issue of reasons for its occurrence is risen; addressees of verbal aggression are identified, explicit and implicit ways of manifestation of verbal aggression are studied at different linguistic levels (lexical, grammatical, graphical means), oppositions "people-the government", "the poor-the rich", "the center-the province", and "the locals-the migrants" actualized in verbal comments are described. At the end of the article, prospects of further study are delineated, which may include the analysis of the semantic uncertainty of texts published in regional media which give rise to conflicts.

Keywords: internet comment, social media, verbal aggression, social tension, ways of manifestation of verbal aggression.

\author{
Фаломкина Ирина Павловна \\ К.филол.н., старший преподаватель, Кемеровский \\ государственный университет \\ falomkina@mail.ru
}

Аннотация: В статье анализируются комментарии пользователей сети Инстаграм с точки зрения проявления речевой агрессии, которая, по мнению автора статьи, с одной стороны, объясняется спецификой интернет-коммуникации, в которой отсутствует целый ряд коммуникативных ограничений, виртуальным характером общения и анонимностью, с другой стороны, является маркером социальной напряженности: уровень речевой агрессии напрямую зависит от уровня интереса к содержанию публикации, а значит от значимости для комментатора события, отраженного в тексте. Самыми волнующими для кузбассовцев темами в период с 1 марта 2019 года по 1 марта 2020 стали плохая экология, массовый оттока жителей из региона, низкий уровень доходов населения, нерациональное распределение бюджета. В работе затрагивается вопрос жанровой специфики интернет-комментария, определяется феномен речевой агрессии, поднимается вопрос о причинах ее возникновения, выявляются адресаты речевой агрессии, исследуются эксплицитные и имплицитные способы проявления речевой агрессии на разных языковых уровнях (лексические, грамматические, графические средства), описываются актуализированные в речевых комментариях оппозиции «народ-власть», «бедные-богатые», «центр-периферия», «местные-мигранты». В конце статьи очерчиваются перспективы дальнейшего исследования, которое может включать анализ порождающей конфликт семантической неопределенности текстов публикаций региональных СМИ.

Ключевые слова: интернет-комментарий, социальные сети, речевая агрессия, социальная напряженность, способы проявления речевой агрессии.

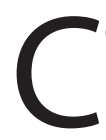

оциальные сети - наиболее динамично развивающийся сегмент российского Интернета. Интернет как особое информационное пространство дает представителю массовой аудитории право участвовать в обсуждении любого резонансного события. Возможность оставлять комментарии под публикациями определяет один из основопо- лагающих принципов интернет-общения - его диалогичность.

Комментарий как жанр интернет-коммуникации представляет собой речевую реакцию на некий текст и на событие, отраженное в этом тексте. При этом реакция эта часто негативная. Т.И. Стексова полагает, что это

Исследование выполнено при финансовой поддержке РФФИ в рамках научного проекта № 20-412-420004 р_а 
делает интернет-комментарий жанром оценочным или императивным, а не информативным, в отличие от научного комментария, комментария-примечания. [1, с. 84]. Отрицательная оценочность, транслируемая как имплицитно, так и явно, является одним из характерных признаков интернет-комментария. При этом стоит отметить «тонкую социальную «чувствительность»» комментария: «любое политическое событие вызывает мгновенную (и множественную) реакцию» [2, с. 131]. Новость или сообщение в соцсетях служат поводом для обсуждения остросоциальных вопросов, в том числе тех, которые не имеют прямого отношения к основной теме сообщения. Комментарий становится одной из форм проявления общественного мнения. Читатели охотно комментируют события, находящие у них эмоциональный отклик. При этом даже позитивные новости могут вызвать речевую агрессию комментатора. Проявление речевой агрессии в тексте комментария, с одной стороны, определяется отсутствием в интернет-коммуникации целого ряда коммуникативных правил и ограничений, присущих реальному общению, с другой стороны, может свидетельствовать, по мнению Т.И. Стексовой, о социальной напряженности [2, с. 81].

Целью нашего исследование является анализ способов проявления речевой агрессии в комментариях как маркера социальной напряженности. Мы обратились к комментариям в региональном инстаграм-паблике, объединяющим 177 тысяч подписчиков, - @kuzbass_news. Авторы инстаграм-блога, представляющего собой неофициальные СМИ, позиционируют его как «самый большой паблик региона». На странице @kuzbass_news [21] освещаются события социальной, экономической, политической жизни региона и России в целом, а также криминальные происшествия.

Эмпирический материал включает комментарии к публикациям в профиле @kuzbass_news в период с 1.03.2019 г. по 1.03.2020 г. При анализе читательских комментариев мы сохраняем авторскую орфографию и пунктуацию, но не включаем эмодзи.

Методы исследования включают лингвистический анализ материала, количественный метод.

Изучению феномена речевой агрессии посвящено немало лингвистических работ $[3,4,5,6]$, однако в силу сложной синтетической природы речевой агрессии [7], существования разнообразных способов ее проявления, учеными не достигнуто единогласия в вопросах дефинирования и определения объема этого понятия. Мы вслед за В.Ю. Апресяном под языковой агрессией понимаем «все типы негативного или критического отношения говорящего к адресату, выраженные при помощи языковых средств» [8, с. 32]. Кроме того, важным при определении речевой агрессии мы считаем целевую установку (намерение) говорящего вызвать негативную реакцию у читающего или слушающего.

Анализ способов проявления речевой агрессии осуществляется современными исследователями в различных аспектах: изучаются агрессивные стратегии и тактики [9, 10, 11, 12, 13], определяются речевые жанры, реализующие агрессивный тип речевого поведения [14, 15], описываются способы проявления речевой агрессии на разных языковых уровнях [16].

Авторы ряда работ обращаются к исследованию отражения социальной напряженности в интернет-дискурсе $[2,17,18]$.

Мы проанализировали 40 самых комментируемых публикаций паблика @kuzbass_news, посвященных региональным событиям, и определили, что наибольший резонанс в обществе вызывали новости об установке новогодней ели на главной площади областного центра (споры велись о целесообразности покупки дорогой ели в период экономической нестабильности). 7 из 40 публикаций, прокомментированных в общей сложности 2572 раза, затрагивают эту тему. Самый популярный пост о новой кемеровской ели за 29 ноября 2019 года был прокомментирован 350 раз.

Таким социальным проблемам, как отток жителей из региона, уровень доходов населения, увольнение рабочих с предприятий угольной сферы, оптимизация медицинских учреждений, перебои в закупках жизненно необходимых лекарств, посвящено 6 публикаций из 40 (1046 комментариев).

5 постов из 40 касаются экологических проблем: выбросов предприятий, автомобилей, смогу, неблагоприятным погодным условиям, необходимости газификации региона. Общее число комментариев - 890.

Деятельность регионального правительства обсуждалась в 3 публикациях (736 комментариев).

Кроме того, кузбассовцы активно обсуждали состояние дорог, общественного транспорта, городской среды, участившиеся случаи нападения бездомных собак.

11 из 40 наиболее популярных публикаций посвящены криминальным новостям. В нескольких публикациях обсуждались курьезные случаи из жизни кузбассовцев.

Объектом комментирования в паблике @kuzbass_ news становится событие, лежащее в основе публикации; текст поста и его элементы; персонажи, упомянутые в публикации; лица, не имеющие прямого отношения к 
теме поста; автор другого комментария; содержание чужого комментария.

Предсказуемо много комментариев, как мы видим, появляется под публикациями, затрагивающими ситуации, которые являются болевыми точками экономической, политической, общественной жизни региона. А как отмечает Т.А. Воронцова, «любая серьезная общественная проблема требует ответа на вопрос: «Кто виноват?»». [3, с. 70]. Комментаторы отвечают на этот вопрос, определяя объект речевой агрессии. Им может стать конкретное лицо:

- администратор инстаграм-аккаунта: Слушай, ты че куришь, когда такие посты публикуешь (16.06.19);

- автор новости, видео-сюжета: Автор редкостный идиот (29.01.20)

- конкретные лица - герои публикации: Больной и не лечится (14.12.19), Ему глазенки выткнуть, пусть побегает! (3.12.19), На вилы его! (3.12.19), да он тупой, расходимся (2.12.19)

- конкретные лица - авторы других комментариев: надоели эти нытики (25.02.20), вы своем уме вообще? какие нахрен машины и туманы? (25.02.20).

Объектом речевой агрессии может являться группа лиц, объединенных по какому-либо признаку, часто по занимаемой должности: Не справляются главы, на лаnamy ux!

Агрессивно оценивается и содержание новости, которая часто представляет собой перепост новости из официальных СМИ (Брееед конечно!!!! (28.02.20); Уже не позорились бы свочми публикациями и советами» (26.02.20)), и мнение автора другого комментария (проcmume, но это уже маразм! (21.02.20), Какую же вы чушь nuwume... (21.02.20)).

Анализ эмпирического материала позволил выявить несколько оппозиций, которые актуализируются в агрессивных комментариях.

Наиболее ярко в текстах комментариев проявляется оппозиция «народ-власть». Комментаторы делятся на две группы: тех, кто одобряет действия властей и тех, кто критикуют власть. Последних гораздо больше. Для номинации первых может быть использована сниженная лексика: А кто в его защиту пишут, это его шныри приближенные а не простой народ (23.12.19); херня ваша елка, ворюги (23.12.19). Либо лексика нейтральная, приобретающая негативную окраску в контексте: безчувственное Оно, яж говорю фейк из администрачии, аккаунт закрыт, фото ребенка, имя хер пойми... (29.11.19); Сейчас начнут орать защитники власти что это обман! (3.12.19); Сейчас защитни- ки елки и власти начнут справедливый народ полоскать... (23.12.19).

Комментаторы подвергают критике большинство поступков представителей власти, практически любую новость из жизни области. Такую стратегию, по мнению Е.Ю. Пановой и В.В. Федорова можно охарактеризовать как «агрессивно-иррациональное восприятие власти, которое не зависит от политических и идейных ориентаций» $[17$, с. 46].

Способами выражения агрессии становится обсценная и инвективная лексика, ненормативные формы наименования чиновников (чинуши, чинушники чиновничье - оценка выражается с помощью словообразовательных средств), глаголы с негативной семантикой, устойчивые выражения с отрицательным оценочным компонентом: Потому что чиновники сожрали наши заработанные деньги (01.03.20); Бред сивой кобылы! Сказать народу правду кишка тонка (23.02.20); народ не обязан содержать дармоедов-госслужащих (21.02.20); Ну да, опять отоговорки чиновников!!! Все куплено!!!! Дышать нечем... (23.02.20); Сначала половину денег стырят всем известные личности... А после этого распилят остаток бабла (25.02.20), власть бандитов (21.02.20); Трындец! И это называется улучшаем экологию Кузбасса! Пустобрехи! (2.12.19).

Используются синтаксические конструкции, выражающие иронию по отношению к адресату: А они изучают, почему из Кемеровской обл. люди убегают. Всем местным министерством голову ломают, все о народе думают...; Что? Опять? Сколько можно повышать? Уже не знаем, куда деньги девать! (28.02.20)

В качестве объекта речевой агрессии часто выступает обобщенный образ представителя власти «чиновник», «депутат», «власть», «они», «вы»: Из года в год одно и то же!!! Куда вы деваете деньги??? Где качественные системы отчистки??; От властей всегда показушная отчетность.

Комментарии относительно представителей власти актуализируют такие социально неодобряемые признаки, как неискренность, стяжательство, жизнь за чужой счет.

Значительная группа агрессивных комментариев отражает оппозицию «богатые - бедные». Речевая агрессия в сторону «богатых» звучит под публикациями, посвященными экологическим проблемам. Богатые мыслятся как виновники сложной экологической обстановки - это владельцы предприятий, отравляющих воздух. Бедные - «простые люди», вынужденные выживать в тяжелых условиях. По отношению к бога- 
тым используются оценочные номинации, глаголы со значением разрушения, уничтожения, наживы: Тоже валю отсюда!!! Пока жиробасы все тут губят, нам делать нечего (01.03.20); Спасибо «азоту» СДС рулит а на здоровье простых людей им наплевать; Вытравят всех скоро, зато карманы набьют себе по полной. Сами же свалят, где экология получше; Хочется плюнуть на это и сорватся с этого города !! Уже прям в наглую нас травят, не стесняясь!!!!! С чьей подачи это все даже гадать не надо!!!... все денег нажраться не может; КОГДА ЖЕ ВЫ НАЖРЕТЕСЬ УЖЕ!!!! ЛЮДИ ВЫНУЖДЕНЫ ДЫШАТЬ ЭТОЙ ГАДОСТЬЮ ИЗ-ЗА ВАС!!!; АУУУУУ МЫ В КИСИЛЕВСКЕ СКОРО КАК В ГАЗОВОЙ КАМЕРЕ ЗДОХНЕМ!!!!! ... ЛИЖ БЫ ШТАНЫ И КАРМАНЫ НАБИТЬ ПОБОЛЬШЕ А НА ЛЮДЕЙ ПЛЕВАТЬ ХОТЕЛИ (3.12.19); БУржуа жиреют, а нород болеет! (2.12.19); Да когда вы уже нажретесь, варюги у кормушки (22.11.19).

Графически речевая агрессия проявляется в многократном повторении восклицательных знаков, сочетании вопросительных и восклицательных знаков, применении прописных букв не по назначению, использовании эмодзи со значением отвращения, возмущения, насмешки. Многоточие, особенно в сочетании с восклицательным знаком, тоже становится маркером агрессии - у комментатора как бы не остается слов для выражения негодования.

«Центр - периферия» - еще одна оппозиция, которую актуализируют агрессивные комментарии.

Речевая агрессия направлена, с одной стороны, на власть, которая, по мнению кузбассовцев, живущих за пределами Кемерова, бездействует в решении проблем периферии, стягивая финансы в областной центр, с другой стороны на жителей Кемерова, которые незаслуженно пользуются всеми благами. А забрали все ресурсы и финансовые, и технические, и культурные. Как ни посмотришь в интернете, то строят все в Кемерово. Открывается - в Кемерово... А то налоги - с нас, а привилегии вам. Еще хватает совести гордиться этим. (28.02.20).

Особенно остро оппозиция «центр - периферия» проявляется в противостоянии Кемерова и Новокузнецка. Уникальная для российских регионов ситуация, когда в области существует два крупных промышленных центра с практически равным числом жителей, рождает среди кузбассовцев споры о том, кто заслуживает статуса столицы. Новокузнечане пренебрежительно называют Кемерово Щегловкой, отсылая к названию села, которое было на месте Кемерова - Щеглово: Опять в Щегловка-срите. Лучше бы в Кузне построили! (28.02.20); Надо в Щегловке повесить такую рекламу. Щегловка - нигдегород и накакгород (14.02.20);
В новокузнецке каждый вечер так, и ничего живем! А то прям бедное Кемерово задыхается посмотрите ка, елку по частям продайте и установите очистные (25.02.20). Для выражения агрессии может использоваться языковая игра: Щегловка-срите по аналогии с Щегловка-сити.

Кемеровчане в ответ высмеивают столичные амбиции новокузнечан, а после курьезной петиции о переименовании Новокузнецка по названию реки Кондома могут назвать Новокузнецк Кондомском: ну да, тебе там в Кондомске виднее (14.02.20).

В анализируемом материале обнаруживается незначительное число комментариев, проявляющих оппозицию «местный - мигрант».

Маркерами речевой агрессии становятся этнонимы с негативной окраской, имена собственные в роли нарицательных, ирония, игра слов: Чуркота только и едет к нам... , уехали достойные, а приехали гастрорбайтеры (01.03. 2020), Иностранец мля, так бы и писали что мастер джамиуд; Где-то их бадяжат в статистику рождаемости, чтоб население больше было, а тут такой поворот - иносранец (10.12.19), Вот так! Сначала нам темненьких подселили, а теперь желтеньких. Вот заживем теперь (21.11.19). Читатели комментируют происшествия с участием мигрантов, отток населения из Кемеровской области, экспансию китайского бизнеса. Последняя тема, более актуальная для Дальнего Востока, вызвала очень скромный отклик кузбасских комментаторов.

Итак, в текстах комментариях в инстаграм-паблике @kuzbass_news были обнаружены различные способы проявления речевой агрессии, которые, по нашему мнению, могут быть признаком социальной напряженности. Агрессивный характер комментариев определяется прежде всего спецификой среды коммуникации, ведь виртуальная среда позволяет комментатору проявлять себя более агрессивно, чем при непосредственном общении. Кроме того, как отмечают Е.Ю. Панова и В.В. Федоров, комментарии имеют «психотерапевтический характер»: если нас не устраивает какая-то ситуации, мы совершаем активные действия, чтобы ее изменить, при этом чем выше градус нашего возмущения, тем более активными становятся действия. В виртуальном пространстве комментарий становится тем самым активным поступком [17, с. 48]. Мы можем предположить, что уровень речевой агрессии тем выше, чем более значимыми для комментаторов являются события, освещенные в новостном паблике. Для создания отрицательной оценки события, явления, личности широко используются лексические, грамматические, графические средства, а также ирония, сарказм, насмешка, 
прямые и скрытые угрозы.

В нашей работе мы не обращались к анализу самого текста публикации, в то время как ряд исследователей (Н.Д. Голев, Л.Г Ким, Е.В Кишина) полагают, что интернет-комментарий может быть рассмотрен сквозь призму конфликта интерпретаций исходного текста. Рассматривая смысловую организацию текста, ученые показывают, как комментарий актуа- лизирует его имплицитные смысловые компоненты [19, с. 19 -34; 20, с. 74-80]. Семантическая неопределённость текстов региональных СМИ, порождающая конфликт интерпретаций, может рассматриваться как одно из проявлений конфликтности и социальной напряженности. Наше дальнейшее исследование мы планируем вести именно в этом направлении.

\section{ЛИТЕРАТУРА}

1. Стексова Т.И. Комментарий как речевой жанр и его вариативность // Жанры речи. Саратов, 2016. С. 81-88.

2. Кирилина А.В., Терентий Л.М. Опыт лингвистической диагностики межнациональной напряженности в интернет-дискурсе // Вопросы психолингвистики. № 27. 2016 С. 130-139.

3. Воронцова Т.А. Формирование объектов речевой агрессии в коллективном когнитивном пространстве // Вестник Челябинского Государственного университета. 2013. № 24 (315). Филология. Искусствоведение. Вып. 82. С. 69-73.

4. Седов К.Ф. Речевая агрессия в межличностном взаимодействии // Прямая и непрямая коммуникация. Саратов: Гунц «Колледж», 2003. С. 196-212.

5. Смирнов П.Ю. Языковые средства выражения речевой агрессии в интернет-коммуникации // Научные ведомости. Сер: Гуманитарные науки. Белгород, 2017. C. 34-42.

6. Щербинина Ю.В. Речевая агрессия. Территория вражды. М.: Форум, 2012. 400 с.

7. Речевая агрессия как свойство информационного пространства. Челябинск: Энциклопедия, 2011. 230 c.

8. Апресян В.Ю. Имплицитная агрессия в языке // Компьютерная лингвистика и интеллектуальные технологии. Третья Международная конференция «Диалог 2003». М.: Флинта-Наука, 2003. С. 32-35

9. Егорова Э.Н. Речевая агрессия и стратегия дискредитации (на примере анализа газетных публикаций) [Электронный ресурс] // Язык и текст langpsy.ru. 2015. Tom 2. №3. URL http://psyjournals.ru/langpsy/2015/n3/Egorova.shtml (дата обращения: 07.07.2020)

10. Иваненко Г.С. Текстовые тактики ухода от правовой ответственности при реализации стратегии дискредитации // Вестник КГУ им. Н.А. Некрасова. Кострома, 2013. № 4. С. $134-137$.

11. Иссерс 0.С. Коммуникативные стратегии и тактики в русской речи: Омск: Омск. Гос. ун-т, 1999. 285 с.

12. Карякин А.В. Стратегия дискредитации как способ реализации речевой агрессии // Вестник Волгоградского государственного университета. Серия 2: Языкознание. 2009. № 2 (10). С. 163-167.

13. Хазиева Р.Р. Дискурсивные стратегии и тактики, реализующие интенцию речевой агрессии в политическом дискурсе СМИ // Вестник ВЭГУ. 2014. № 2 (70). C. 192-198.

14. Комалова Л.Р. Жанры агрессивного речевого поведения // Проблемы языка. Сборник научных статей по материалам Пятой конференции-школы «Проблемы языка: взгляд молодых ученых». 2017. С. 139-153.

15. Курьянович А.В. Инвективные речевые жанры в пространстве современной межличностной коммуникации // Вестник Томского государственного педагогического университета. 2005. № 3 (48). С. 106-112.

16. Курьянова И.В. Маркеры речевой агрессии в интернет-коммуникации при исследовании текстов экстремистской направленности // Вестник Московского государственного лингвистического университета. Гуманитарные науки. 2018. № 6 (797). С. 29-38.

17. Панова Е. Ю. Федоров В.В. Глас народа: комментарии к новостям городского портала как мониторинг социальной напряженности // Знак: Проблемное поле медиаобразования. Челябинск, 2015. № 2(16). С. 46-51.

18. Стексова Т.И. Речевая агрессия в интернет-комментариях как проявление социальной напряженности // Политическая лингвистика. Екатеринбург, 2013. № 3. С. 77-81.

19. Голев Н.Д., Ким Л.Г. Обыденные политические интернет-комментарии в зеркале конфликта интерпретаций // Социально-когнитивное функционирование языка. Кемерово, 2017. С. 19-34.

20. Кишина Е.В. Когнитивная реализация речевых конфликтов // Социально-когнитивное функционирование языка. Кемерово, 2017. - С. 74-80.

21. https://instagram.com/kuzbass_news?igshid=1g5f6jbg0p4fh

(c) Фаломкина Ирина Павловна (falomkina@mail.ru). 